\title{
Ethics of Sham Surgery: Perspective of Patients
}

\author{
Samuel A. Frank, MD, ${ }^{1 *}$ Renee Wilson, MA, ${ }^{2}$ Robert G. Holloway, MD, MPH, ${ }^{2}$ \\ Carol Zimmerman, RN, ${ }^{2}$ Derick R. Peterson, $\mathrm{PhD},{ }^{3}$ Karl Kieburtz, MD, MPH, ${ }^{2}$ and \\ Scott Y.H. Kim, MD, $\mathrm{PhD}^{4}$ \\ ${ }^{I}$ Department of Neurology, Boston University School of Medicine, Boston, Massachusetts \\ ${ }^{2}$ Department of Neurology, University of Rochester, Rochester, New York \\ ${ }^{3}$ Department of Biostatistics and Computational Biology, University of Rochester, Rochester, New York \\ ${ }^{4}$ Department of Psychiatry, the Bioethics Program, and the Center for Behavioral and Decision Sciences in Medicine, University \\ of Michigan, Ann Arbor, Michigan
}

\begin{abstract}
Sham surgery is used as a control condition in neurosurgical clinical trials in Parkinson's disease (PD) but remains controversial. This study aimed to assess the perspective of patients with PD and the general public on the use of sham surgery controls. We surveyed consecutive patients from a university-based neurology outpatient clinic and a community-based general internal medicine practice. Background information was provided regarding PD and two possible methods of testing the efficacy of a novel gene transfer procedure, followed by questions that addressed participants' opinions related to the willingness to participate and permissibility of blinded and unblinded trial designs. Two hundred eighty-eight (57.6\%) patients returned surveys. Patients with PD expressed
\end{abstract}

less willingness to participate in the proposed gene transfer surgery trials. Unblinded studies received greater support, but a majority would still allow the use of sham surgery. Those in favor of sham surgery were more educated and more likely to use societal perspective rationales. Patients with PD are more cautious about surgical research participation than patients with non-PD. Their policy views were similar to others', with a majority supporting the use of sham controls. Future research needs to determine whether eliciting more considered judgments of laypersons would reveal different levels of support for sham surgery. (C) 2007 Movement Disorder Society

Key words: sham surgery; Parkinson's disease; placebo controlled trials; gene therapy.
The use of placebo or sham surgery controls in randomized trials of surgical interventions is becoming more common in Parkinson's disease (PD) research ${ }^{1-5}$ but is not without controversy. ${ }^{6}$ Aside from questions surrounding informed consent, the controversy over sham surgery controls involves two predominant issues. The first is whether a randomized clinical trial with sham surgery control is a scientifically superior method to test novel neurosurgical interventions for PD. PD researchers believe that a placebo surgery should be used as a control condition when testing a novel surgical intervention.? Second, are the risks to subjects in randomized clinical trials with sham surgery controls reasonable in relation to

*Correspondence to: Dr. Samuel Frank, 715 Albany St., Collamore 329, Boston, MA 02118. E-mail: samfrank@bu.edu

Received 15 February 2007; Revised 13 August 2007; Accepted 14 September 2007

Published online 25 October 2007 in Wiley InterScience (www. interscience.wiley.com). DOI: 10.1002/mds.21775 the potential benefit to the subjects and to society? Some of the risks associated with sham surgery in PD have been summarized, ${ }^{8}$ but the opinion of whether the risks and burdens associated with sham surgery are too high requires input from the patients who are the potential study participants.

Patients who are currently experiencing the symptoms of PD may be better able to compare the risks and benefits and best answer whether the risks to individuals is worth the benefit to science and society. Therefore, we developed a hypothetical scenario describing a gene transfer intervention with promising initial results and surveyed patients regarding their views on the use of sham surgery as the placebo in controlled surgical trials.

\section{PATIENTS AND METHODS}

\section{Participants}

From May 24, 2004 through September 9, 2004, we surveyed consecutive patients with and without PD from 
a neurology clinic with a high proportion of patients with PD. Patients with dementia were excluded. As a comparison group, the survey was also administered to patients from a community-based general internal medicine practice.

\section{Survey Instrument}

The survey consisted of four pages of background information followed by three questions. We described the motor symptoms typically reported in moderate to advanced PD. We then presented a scenario detailing a hypothetical gene transfer intervention. The respondents were asked to suppose that a successful phase I study of a novel gene transfer therapy for PD had been conducted on eight subjects. They were told, "The researchers did not find any significant short-term negative effects from the gene transfer and there was some evidence that gene transfer surgery reduced PD symptoms." Second, they were asked to consider two potential randomized, controlled trial designs for a follow up study involving 40 subjects, the goal of which was to test the efficacy and safety of the gene transfer procedure. The first possibility was an open, unblinded study in which 20 subjects would be randomized to receive gene transfer surgery plus their usual medications or usual medications only. In the second possible hypothetical trial, 20 subjects would be randomized to undergo gene transfer surgery or sham surgery, in which sham surgery consisted of drilling two full thickness burr holes. For the sham controlled study, the respondents were told that if the gene transfer surgery turned out to be safe and effective, "the participants who undergo sham surgery will [later] be offered the gene transfer procedure using the predrilled holes." The description concluded with a discussion of the scientific reasoning behind using placebo surgery and an explanation of the potential risks and benefits of gene transfer therapy for PD.

Participants were asked to imagine that they themselves had moderate to advanced PD as described in the survey. They were then asked if they would participate in an unblinded study, a blinded study, or not participate at all in a gene transfer trial. The second question asked participants to suppose they were members of an ethics review committee whose job it is to decide whether to allow certain studies. The purpose of this exercise was to frame the question from a societal perspective in order to distinguish the decision from a personal preference perspective. They then decided whether they would allow an unblinded study and a blinded study. Finally, they were asked if the burdens and risks of sham surgery to subjects were justified by the potential benefits to society. Participants could justify their choices immediately after an- swering each question. For question one ("which study would you participate in?"), we provided a list of six options based on consistent responses from previous studies to justify the decision. For the other questions, participants were prompted to justify decisions with an open-ended question.

\section{Analysis}

We tabulated frequency data and analyzed the qualitative data from the open comments as follows. Two of the authors (SK and RW) read all the comments together and devised a coding scheme that was later modified with input from two other authors (RH and SF). For each question, we categorized comments with similar content related to individual questions. Each comment was independently coded by three of the authors; the final code was assigned when there were two of three or better agreement. When coding the 758 comments, agreement among at least two of three coding judges occurred in $93.1 \%$ of cases and the rest were resolved by consensus meeting. Some respondents made lengthy comments that required more than one code per comment.

Except for age, the data were categorical, and therefore all unadjusted comparisons were performed using $\chi^{2}$ tests of independence for the two-way contingency tables. Age was compared using ANOVA. Multiple logistic regression was used to compare the three patient groups (PD, non-PD neurology, primary care), adjusted for age group (5-year groupings between ages 40 and 70, and treating "not reported" as a separate category), gender, education (high school or less, some college, college degree, post college degree), marital status (married, unmarried), and potential two-way interactions. Separate binary logistic regression models were fit for each of five binary outcomes: (1) would participate versus would not participate in any surgical trial, (2) participate in blinded versus open (excluding those who would not participate), (3) allow open versus not allow open, (4) allow sham surgery versus not allow sham, and (5) the risks are or are not worth the potential benefit to society. To simplify the final models, adjacent categories of ordered categorical covariates were collapsed. Once the functional forms of the main effect terms were selected, all-subsets regression was again used to consider all possible two-way interactions between the remaining predictors. To make the same modeling adjustments in all five final models, any predictor that was selected for one outcome was retained for the others as well. In the final models, the Wald test $(\mathrm{df}=2)$ was used to test whether patient group was independent of each outcome, adjusted for the demographic covariates, and odds ratios with corresponding 95\% confidence intervals and $P$-values were used to 
TABLE 1. Characteristics of groups

\begin{tabular}{|c|c|c|c|c|c|}
\hline & PD & Non-PD neurology & Primary care & All patients & $P^{*}$ \\
\hline $\mathrm{n}$ & 56 & 113 & 119 & 288 & \\
\hline Age (SD) & $66.8(10.0)$ & $51.7(15.8)$ & $57.0(9.2)$ & $56.8(13.4)$ & $<0.001$ \\
\hline Gender & & & & & 0.001 \\
\hline No. $(\%)$ of females & $32(60.4)$ & $76(68.5)$ & $100(84.7)$ & $208(73.7)$ & \\
\hline Education (no./\%) & & & & & 0.13 \\
\hline High school or less & $15(27.3)$ & $19(17)$ & $14(11.9)$ & $48(16.8)$ & \\
\hline Some college & $15(27.3)$ & $27(24.1)$ & $27(22.9)$ & $69(24.2)$ & \\
\hline College degree & $9(16.4)$ & $32(28.6)$ & $34(28.8)$ & $75(26.3)$ & \\
\hline Post college & $16(29.1)$ & $34(30.4)$ & $43(36.4)$ & $93(32.6)$ & \\
\hline Ethnicity (no./ \%) & & & & & 0.26 \\
\hline White & $55(98.2)$ & $110(98.2)$ & $107(92.2)$ & $272(95.7)$ & \\
\hline Black & $1(1.8)$ & $1(0.9)$ & $6(5.2)$ & $8(2.8)$ & \\
\hline Other & 0 & $1(0.9)$ & $3(1.6)$ & $4(1.4)$ & \\
\hline Marital status (no./\%) & & & & & 0.002 \\
\hline Married & $48(85.7)$ & $71(63.4)$ & $77(65.8)$ & $196(68.7)$ & \\
\hline Divorced/separated & $4(7.1)$ & $17(15.2)$ & $22(18.8)$ & $43(15.1)$ & \\
\hline Single/never married & 0 & $21(18.8)$ & $11(9.4)$ & $32(11.2)$ & \\
\hline Widowed & $4(7.1)$ & $3(2.7)$ & $7(6.0)$ & $14(4.9)$ & \\
\hline
\end{tabular}

Missing data is due to participants not providing answers to demographic questions.

$* \chi^{2}$ tests were used for comparisons of categorical data; ANOVA used for comparison of continuous data.

summarize adjusted differences between pairs of patient groups.

All subsets analysis selected four age groups $(<50$, $50-64,65+$, and "not reported"), three education levels (high school or less, some college or a college degree, post college degree), and both gender and marital status were retained. There was insufficient evidence to justify the inclusion of any interaction terms.

\section{Human Subjects}

The University of Rochester and the University of Michigan reviewed the protocol and deemed this survey exempt from IRB review.

\section{RESULTS}

Three hundred surveys were distributed at the neurology clinic and 200 surveys at the primary care clinic. One hundred sixty-nine (56.3\%) and 119 (59.5\%) surveys were returned from the neurology and primary care clinics, respectively. Among the neurology clinic participants, the patient diagnoses included PD (33.1\%), dystonia $(9.5 \%)$, essential tremor $(6.5 \%)$, huntington disease $(2.4 \%)$, and others $(35.5 \%) .88 .5 \%$ of patients answered all questions. The lowest response rate for any single question was $94.6 \%$ except age, which had a response rate of $76.4 \%$.

Patients with PD were older, with a female majority, and more patients with PD were married when compared with the other groups (Table 1). Patients with PD were less willing to participate in the proposed trials (Table 2). $34 \%$ of patients with PD stated that they would not participate in either of the hypothetical gene transfer surgery trials, compared to $6.4 \%$ of the patients with non-PD neurology and $10.4 \%$ of the primary care patients $\left(\chi^{2}=26.0\right.$, df $\left.=4, P<0.001\right)$.

When asked to give their views, supposing they were members of an ethics review committee, most of the respondents, regardless of group, favored allowing both the sham surgery study and the open study, although the support for the open study was higher (Table 3). Comments by the minority who opposed allowing the open trial $(17 \%)$ were predominantly "scientific" rationales, with $61 \%$ pointing to the scientific inadequacy. Among those who would allow the open study, $27 \%$ of comments indicated that the risks were outweighed by the overall benefit to science and society and $22 \%$ found blinding per se objectionable. Comments by those in

TABLE 2. Which study would you choose to participate in?

\begin{tabular}{llcrr}
\hline & PD & Non-PD neurology & Primary care & Total \\
\hline Unblinded n $(\%)$ & $22(41.5)$ & $60(55)$ & $63(54.8)$ & $145(52.5)$ \\
Blinded n $(\%)$ & $13(24.5)$ & $42(38.5)$ & $40(34.8)$ & $95(34.4)$ \\
Would not participate n $(\%)$ & $18(34)^{\mathrm{a}}$ & $7(6.4)$ & $12(10.4)$ & $37(13.4)$ \\
\hline
\end{tabular}

${ }^{\mathrm{a}} P<0.001, \chi^{2}=26.0, \mathrm{df}=4$ 
TABLE 3. Permissibility of unblinded and sham control studies

\begin{tabular}{|c|c|c|c|c|c|}
\hline & PD & $\begin{array}{l}\text { Non-PD } \\
\text { neurology }\end{array}$ & $\begin{array}{l}\text { Primary } \\
\text { care }\end{array}$ & Total & Comments (\% of responses) \\
\hline \multicolumn{6}{|l|}{$\begin{array}{l}\text { Suppose you are a member } \\
\text { of an ethics review } \\
\text { committee. . Would } \\
\text { you allow the } \\
\text { unblinded study of the } \\
\text { gene transfer } \\
\text { intervention that we } \\
\text { have been discussing? }\end{array}$} \\
\hline $\begin{array}{l}\text { Definitely or probably } \\
\text { allow }\end{array}$ & $44(81.4)$ & $95(85.6)$ & $96(81.4)$ & $235(83)$ & $\begin{array}{l}\text { An unblinded study could lead to progress in } \\
\text { research or provide useful information and } \\
\text { the risk to subjects is acceptable in } \\
\text { comparison to potential benefits for } \\
\text { science and society }(27 \%) \\
\text { It is better if group assignment is transparent } \\
\text { and subjects are informed of whether they } \\
\text { are receiving gene or not ( } 22 \%) \\
\text { The control group faces less risk than with } \\
\text { sham surgery }(11 \%) \text {. }\end{array}$ \\
\hline $\begin{array}{l}\text { Definitely or probably not } \\
\text { allow }\end{array}$ & $10(18.5)$ & $16(14.4)$ & $22(18.6)$ & 48 (16.9) & $\begin{array}{l}\text { There is too high a chance of the placebo } \\
\text { effect and bias with the unblinded design } \\
(37 \%) \\
\text { The results from an unblinded study would } \\
\text { not be as scientifically sound and } \\
\text { conclusive ( } 24 \%) \\
\text { The risk-benefit ratio associated with the } \\
\text { unblinded design is unacceptable ( } 7 \%) \\
\text { Do not approve of any study involving } \\
\text { surgery }(7 \%) \text {. }\end{array}$ \\
\hline \multicolumn{6}{|l|}{$\begin{array}{l}\text { Would you allow the } \\
\text { blinded (sham surgery } \\
\text { control design) study } \\
\text { of the gene transfer } \\
\text { intervention? }\end{array}$} \\
\hline $\begin{array}{l}\text { Definitely or probably } \\
\text { allow }\end{array}$ & $30(54.6)$ & $60(53.5)$ & $64(54.7)$ & $154(54.3)$ & $\begin{array}{l}\text { The blinded study is the only way to get } \\
\text { definitive, conclusive results }(24 \%) \\
\text { The blinded design is acceptable if adequate } \\
\text { informed consent is in place }(20 \%) \\
\text { The risk-benefit ratio with the blinded study } \\
\text { is acceptable ( } 18 \%) \\
\text { The risks are outweighed by potential } \\
\text { benefits to society, subjects, and science } \\
(18 \%) \text {. }\end{array}$ \\
\hline $\begin{array}{l}\text { Definitely or probably not } \\
\text { allow }\end{array}$ & $25(45.5)$ & $52(46.5)$ & $53(45.3)$ & $130(45.8)$ & $\begin{array}{l}\text { There is too much risk and the procedures } \\
\text { are too invasive }(28 \%) \\
\text { Asking the patients to accept risk without } \\
\text { benefit is unacceptable ( } 25 \%) \\
\text { The blinded design and use of sham surgery } \\
\text { is unethical }(12 \%) \text {. } \\
\text { It is not ethical to ask people to participate } \\
\text { in a study where they do not know } \\
\text { whether they will receive the gene or not } \\
(11 \%) \text {. }\end{array}$ \\
\hline
\end{tabular}

All responses are $\mathrm{n}(\%)$ of the group.

favor of the blinded (i.e., sham) study tended to be comparative value statements that appeared to reflect a balancing of opposing considerations, or pointed to the role of informed consent as justifying the study. Those opposed to sham control design, on the other hand, tended to focus on the invasive, risky nature per se (rather than using comparative value statements), focused on the risk-benefit for the participants only, or were opposed to blinding or sham surgery in general.

When asked if the burdens and risks of surgery without expectation of benefit to the subject was justified by the potential benefits to science and to society, $56 \%$ of 
respondents thought the risk was justified, without significant differences between the groups.

In the multiple logistic regression analyses, patient group significantly predicted willingness to participate in the proposed surgical trials (i.e., those willing to participate in blinded or unblinded trial vs. those not willing to participate in either surgical trial). The PD group was significantly less willing to participate in either of the proposed surgical trials compared to patients with non-PD neurology $[\mathrm{OR}=0.10,95 \%$ CI $(0.03-0.33)]$ and patients with primary care $[\mathrm{OR}=0.25,95 \% \mathrm{CI}$ $(0.09-0.68)](P<0.001$ on 2 df $)$. Those with a post college degree were more likely to approve of the use of sham surgery controls under the hypothetical circumstances compared to subjects with a high school education or less $[\mathrm{OR}=4.69,95 \% \mathrm{CI}(2.12-10.41)]$. They were also more likely to agree that for the proposed trials, the burdens, and risks of sham surgery to subjects are justified by the potential benefits to society [(OR = $3.66,95 \%$ CI $(1.59-8.42)]$.

\section{DISCUSSION}

When presented with a hypothetical case about research involving gene transfer surgery, patients with PD expressed less willingness to participate in the proposed surgical trials. Patients with chronic illness adapt to their disabilities and therefore, individuals with PD might feel they have less to gain or more to lose from the benefits and risks associated with trials involving surgery. Previous studies in PD have confirmed this view, showing that severity of PD did not predict willingness to participate in research. ${ }^{9}$ In fact, there was some indication that more affected subjects were less willing, consistent with adaptation playing a bigger role than the intuition that more severe illness means more willingness. Particular personality traits may also be present in patients with movement disorders that increase risk aversiveness. ${ }^{10}$ Alternatively, patients with non-PD may overestimate the impact that PD disability may have on them or underestimate retained function. ${ }^{11,12}$ Therefore, they may assume more risk and overestimate the benefits of trials involving surgery.

Using a hypothetical scenario evaluating a novel surgical intervention for PD, most patients endorsed sham surgery as an ethically acceptable control condition. What distinguishes those who endorse sham surgery from those who would not? Whether participants had PD or not, education seems to play a strong role in people's willingness to take a more societal perspective and balance the burdens to participants with the overall scientific and societal benefit. This trend is supported by the qualitative comments given by those who would allow sham surgery, as the supporters tended to give compar- ative value statements. In contrast, those opposed to sham surgery appeared to have an intrinsic objection to blinding, and to focus on the invasive nature of the sham procedure per se. It appears that those who are supportive of sham controls are willing and able to understand and take on a societal perspective in giving their answers, whereas those who were opposed to it tend to focus on a more narrow view or simply state their disapproval. This finding raises important questions about whether further intensive education and discussion about the scientific rationales and the actual risks and benefits of sham controls may affect people's opinions. (For instance, a recent review of the adverse effects of sham surgery in four small PD trials did not find any serious adverse events and no increased risk of adverse events compared to the active intervention arms. ${ }^{8}$ ) Given the complexity of the topic, it may be that laypersons, especially those with less education, may need more opportunity to learn and deliberate on the issues.

When comparing the responses of the subjects in this study with PD researchers who were presented the same hypothetical scenario, PD clinical researchers were more skeptical about open studies (only 50\% would allow it) and more supportive of sham controlled studies (94\% would support it). ${ }^{7}$ However, it is notable that under the same hypothetical circumstances, the patients who would allow sham controls expressed similar reasoning for the permissibility of sham surgery as the clinical researchers. Studies are needed to determine if the gap between patients and researchers can be closed if patients are given more in depth education regarding clinical trial design, potential benefits and possible risks to individuals and society, and are given a chance to deliberate further on the issues or, conversely, if researchers are further educated about issues of critical importance to potential subjects.

There are several limitations of this study. First, we used a hypothetical scenario requiring role-play for participants without advanced PD. Further research is needed to confirm our findings in patients actually considering trial participation and if these findings differ for different types of invasive interventions with unique risk/benefit profiles. Second, since participants were not examined for this study, there was no measure of how many participants had to role-play having advanced PD. Therefore, we cannot determine if degree of disability affects responses. Third, compared to the general PD population, a higher proportion of participants in this study were female, but ethnicity and education level were comparable. ${ }^{13,14}$ In fact, a disproportionate number of women have participated in surgical trials involving sham surgery (94 of 176, 53\%)..$^{1-5}$ In addition, our multivariate analyses were adjusted for gender, and identified no gender interactions, and thus findings can be interpreted to 
apply equally to both men and women. Fourth, the overall response rate in this study was $57.6 \%$, and the number of nonresponders in all groups was similar. The subjects in this study may have been biased and more inclined to participate in research since they chose to participate in this study. Finally, general internal medicine and patients with non-PD were used as comparison groups but may not necessarily represent overall public views.

The nature of this study limits the ability to generalize the findings in our study to patients in practice or to other interventions with different risk and benefit profiles. The participants for this study were not being recruited for any other study and were specifically told so during the consenting process. For the future, studies of persons in actual clinical trials involving sham surgery may provide further insight into this discussion.

In summary, patients with PD, when compared with patients with non-PD neurology or primary care, may have adapted to their chronic illness and may not be so desperate that they would be more eager to participate in risky research. In fact, they appear more cautious. Further, across all three groups, although the support for an unblinded study is higher than the blinded sham study, a majority support the sham control study to test the efficacy of a hypothetical novel gene transfer intervention. This support appears to be related to higher educational background and a willingness to compare and balance competing values from a scientific and societal perspective.

Acknowledgments: This study was supported as a subproject of U54-NS45309 from the National Institute of Health. This project was also partially supported by Grant Number 1 UL1 RR024160-01 from the National Center for Research Resources (NCRR), a component of the National Institutes of Health (NIH), and the NIH Roadmap for Medical Research, and its contents are solely the responsibility of the authors and do not necessarily represent the official view of NCRR or NIH. Information on NCRR is available at http://www.ncrr.nih.gov/. Information on Re-engineering the Clinical Research Enterprise can be obtained from http:// nihroadmap.nih.gov/clinicalresearch/overview-translationa- 1.asp. Dr. Kim is also supported by NIH grant K23 MH64172 and is a Greenwall Faculty Scholar in Bioethics. Dr. Holloway is supported by NIH grant K24 NS42098. We thank the patients who participated and Drs. Pamela Sloan and Charlene Conners for help with recruitment.

\section{REFERENCES}

1. Lang AE, Gill S, Patel NK, et al. Randomized controlled trial of intraputamenal glial cell line-derived neurotrophic factor infusion in Parkinson disease. Ann Neurol 2006;59:459-466.

2. Freed CR, Greene PE, Breeze RE, et al. Transplantation of embryonic dopamine neurons for severe Parkinson's disease. N Engl J Med 2001:344:710-719.

3. Freeman T, Watts R, Hauser RA, et al. A prospective, randomized, double-blind, surgical placebo-controlled trial of intrastriatal transplantation of fetal porcine ventral mesencephalic tissue (NeurocellPD) in subjects with Parkinson's Disease. Exp Neurol 2002;175:426.

4. Olanow CW, Goetz CG, Kordower JH, et al. A double-blind controlled trial of bilateral fetal nigral transplantation in Parkinson's disease. Ann Neurol 2003;54:403-414.

5. Nutt JG, Burchiel KJ, Comella CL, et al. Randomized, doubleblind trial of glial cell line-derived neurotrophic factor (GDNF) in PD. Neurology 2003;60:69-73.

6. Macklin R. The ethical problems with sham surgery in clinical research. N Engl J Med 1999;341:992-996.

7. Kim SY, Frank S, Holloway R, Zimmerman C, Wilson R, Kieburtz K. Science and ethics of sham surgery: a survey of Parkinson disease clinical researchers. Arch Neurol 2005;62:1357-1360.

8. Frank S, Kieburtz K, Holloway R, Kim SY. What is the risk of sham surgery in Parkinson disease clinical trials? A review of published reports. Neurology 2005;65:1101-1103.

9. Kim S, Holloway R, Frank S, Beck C, Zimmerman C, Wilson R, Kieburtz K. Volunteering for early phase gene transfer research in Parkinson's disease. Neurology 2006;66:1010-1015.

10. Chatterjee A, Jurewicz EC, Applegate LM, Louis ED. Personality in essential tremor: further evidence of non-motor manifestations of the disease. J Neurol Neurosurg Psychiatry 2004;75:958-961.

11. Ubel PA, Loewenstein G, Schwarz N, Smith D. Misimagining the unimaginable: the disability paradox and health care decision making. Health Psychol 2005;24(4 Suppl):S57-S62.

12. De Wit GA, Busschbach JJ, De Charro FT. Sensitivity and perspective in the valuation of health status: whose values count? Health Econ 2000;9:109-126.

13. Frigerio R, Elbaz A, Sanft KR, et al. Education and occupations preceding Parkinson disease: a population-based case-control study. Neurology 2005;65:1575-1583.

14. de Lau LM, Giesbergen PC, de Rijk MC, Hofman A, Koudstaal PJ, Breteler MM. Incidence of parkinsonism and Parkinson disease in a general population: the Rotterdam Study. Neurology 2004;63: $1240-1244$. 